\title{
TOWARDS AN UNCERTAINTY FRAMEWORK FOR PRODUCT SERVICE SYSTEMS OF SYSTEMS
}

\author{
Fakhfakh, Sarra (1,2); Hein, Andreas Makoto (1); Jankovic, Marija (1); Chazal, Yann (2) \\ 1: CentraleSupélec; 2: RENAULT
}

\begin{abstract}
Product Service Systems (PSS) are increasingly complex and collaborative. For instance, manufacturing companies, service providers, and other companies collaborate and jointly develop and operate a PSS (ex: smart grid), where its constituent elements are managed and operated independently. Managerial independence and operational independence are commonly considered key characteristics of a System of Systems (SoS). Hence, a collaborative PSS exhibits System of Systems (SoSs) characteristics. These systems have previously been introduced as Product Service Systems of Systems (PSSoSs). In this paper, we propose to identify relevant uncertainties in the PSSoS design process. For this purpose, we go beyond the PSSoS concept definition and propose a comprehensive framework for PSS and PSSoS characterization. Moreover, based on both a literature review and an industrial diagnosis, we identify PSSoSs-specific design uncertainties.
\end{abstract}

Keywords: Product-Service Systems (PSS), System of Systems, Uncertainty, Complexity

\section{Contact:}

Fakhfakh, Sarra

CentaleSupéléc

Laboratoire Génie Industriel (LGI)

France

sarra.fakhfakh@centralesupelec.fr 


\section{INTRODUCTION}

Different domains propose a variety of definitions for Product Service Systems (PSS) (Haase et al., 2017; Park et al., 2012; Tukker, 2015). In engineering design, a Product Service System (PSS) is commonly defined by its constituent elements: Products, Services, Supporting networks and Infrastructure (Mont, 2002). A collaborative PSS is a bundle of interoperable systems developed and managed by different actors each one aiming at more competitiveness and sustainability (Mont, 2002). Collaborative PSS features can be seen as similar to Systems of Systems (SoSs) features (Estrada and Romero, 2016; Hein, Poulain, et al., 2018b). Hence, based on Maier's (1996) definition of a SoS, Hein et al. (2018a) introduce the concept of a Product Service System of Systems (PSSoSs) defined as "a set of products, services, infrastructures, and networks where its constituent elements exhibit operational and managerial independence".

PSSoSs are already being developed and deployed by industry. For instance, a large automotive company, an energy provider and an infrastructure manager collaborate and jointly develop and operate PSSs (EV2G) (Chazal, 2018). These PSSs involve different and heterogeneous systems jointly capable of fulfilling customer needs, each of them operated and managed by independent companies. More generally, in the context of PSSoS, each actor can develop, manage and/or operate product(s), service(s), PSS(s) and/or infrastructure(s). Actors can also share the development, management and/or operation of Product(s), Service(s), PSS(s) and/or infrastructure(s) (Hein, Poulain, et al., 2018b).

The multitude of possible Product Service combinations and allocation of roles among actors increases PSSoS complexity compared to "classic" PSS. Thus, PSSoS introduce the new challenge of defining the collaborative value proposition (Hein, Chazal, et al., 2018a). Design for interoperability between the PSSoS' constituent elements is another challenge. In the following, we present an example for a design challenge related to interoperability in PSSoS. While a service provider develops intangible services able to interoperate with tangible products throughout their lifecycle, the responsibility of a company in the manufacturing industry for its product extends to its use phase and disposal and covers its whole lifecycle. Moreover, product lifecycles are usually longer than services lifecycles. The fact that service lifecycle is more rapidly evolving introduces additional difficulties and uncertainties in the PSSoS development.

In this paper, we propose to identify relevant uncertainties in the PSSoS design process. For this purpose, we propose a comprehensive framework allowing for PSS and PSSoS characterization, from which these uncertainties can be derived. The aim is to identify uncertainties in order to support overall PSSoS development. The structure of the paper is as following. In section 2, we consider the literature pertaining to both PSS and SoS as few research addresses the PSSoS concept. Moreover, we also address different PSSs and SoSs specific uncertainty definitions and modelling. In Section 3, we describe the adopted research approach. Section 4 details the proposed characterisation of PSS and PSSoS. In section 5, identification of PSSoS uncertainties is discussed with regard to existing literature as well as identified industrial needs. We finally conclude by providing future research avenues in section 6 .

\section{LITERATURE REVIEW}

PSS and SoS have been traditionally discussed separately in literature. Hence, we propose to discuss both PSS and SoS characteristics in order to identify PSSoS characteristics. Moreover, uncertainties related to PSS and SoS development might be different with regard to their different characteristics. In this section, we propose to discuss different types of uncertainties pertaining to PSSoS characteristics.

\subsection{PSS SoS characterizations}

The PSS typology presented in (Tukker, 2004) is one of the most used in the literature. In this typology, a PSS is defined as a business model. A distinction is made between product-oriented PSSs, use-oriented PSSs, and result-oriented PSSs. The differentiating criteria between these three PSS types are mainly the ownership of the product and the payment method (Aurich et al., 2010). Tukker's typology gives a business perspective on PSSs but lacks insight on engineering difficulties related to PSSs development. Meier et al. (Meier et al., 2010) suggest a systems engineering oriented typology for PSSs. The authors distinguish "Service Products", "Extended Products" and "Industrial Product Service Systems". The differentiation between the three types of PSSs is based upon the engineering 
development methods (Independent product and service engineering, Machine/ Product oriented engineering and simultaneous service and systems' engineering respectively). Both typologies describe the decreasing product-centricity of the PSS or as one can define it's increasing heterogeneity. Product-oriented PSS, use-oriented PSS, and result-oriented PSS could be equivalent to "Service Products", "Extended products", and "Industrial Product Service Systems" respectively.

Most of the literature underlines these three PSS characteristics: customer orientation (Manzini and Vezzoli, 2003), sustainability (Pieroni et al., 2017), and heterogeneity (Meier et al., 2010; Sassanelli et al., 2016; Song and Sakao, 2017). Heterogeneity features can further be refined and related to products and services bundles (Song and Sakao, 2017), the diversity in service types (Sassanelli et al., 2016) and the variety of stakeholders expectations (Meier et al., 2010).

Other characteristics are more specifically relevant for user-oriented PSSs and result-oriented PSSs. In use-oriented and result-oriented PSSs, there is a continuous delivery of a service that needs to be supported through the entire life-cycle. As customer needs evolve, (Sakao et al., 2009; Song, 2017) there is a need to be able to dynamically adapt PSS to satisfy these evolutions. This is linked to the notion of evolvability in the literature (Maleki et al., 2017).

As for the SoS characteristics, several research underlined the following characteristics: independence (managerial \& operational) of their elements, their evolutionary nature, emergent behaviours, geographic distribution, interoperability, complementarity and holism (Keating and Katina, 2011; Maier, 1996). Baldwin et al. (2011), focuses on the taxonomy with regard to increasing complexity. Authors distinguish between a simple system, a complicated system, a complex system, an adaptative system, a System of Systems, a collaborative System of Systems and, a complex adaptative system. The taxonomy is based upon 7 characteristics or attributes: Autonomy, Connectivity, Belonging, Emergence, Diversity, Self-organization, and Adaptability (Sauser et al., 2009).

\subsection{PSS SoS related uncertainties}

One can identify several research streams that identify and tackle the notion of development related uncertainties: engineering design, PSS literature, Innovation management and System of Systems literature. In this paper, we consider uncertainty as «a potential deficiency in any phase or activity of the process, which can be characterized as not definite, not known or not reliable» (Kreye, 2011).

In the design engineering literature, one of the most used classification in product design is the one proposed by De Weck et al. (2007) suggesting a classification of sources of uncertainties for early design. The classification includes product, use, corporate, market, and political and cultural contexts as sources of uncertainty.

In the PSS literature, several research proposes PSS related uncertainties (Hernandez et al., 2018; Herzog et al., 2014; Kumar et al., 2013, p. 91,96).

In (Hernandez et al., 2018), the PSS specific uncertainty classification covers Environmental, Organizational, Relational, Technical and Resource uncertainty. This classification is interesting with regard to PSSSoS as authors propose under Technical uncertainty type: uncertainties related to hard/software combination, service definition, forecasting timing and scale of service, Systemic integration (Service + Product). As for Relational uncertainty, it covers uncertainties related to customer and collaboration partners. Reim et al. (2014) in particular address behavioural uncertainties related to PSSs. The increased service content of a PSS leads to more value co-creation with the customer but also increases the risks of customers' opportunistic behaviour. Herzog et al. (2014) classify PSS uncertainties according to three main classes constraints/Requirements, system context, and development processes. This classification is relevant for PSSoSs development as it covers the whole PSS lifecycle and integrates the PSS evolvability through changing customers' needs. The uncertainty classification presented in (Kumar et al., 2013) appears to be the most comprehensive and includes: Market uncertainty, Company uncertainty, Environment uncertainty, Uncertainty of product functioning, Product function uncertainty, Uncertainty of innovative services, PSS integration uncertainty, Supplier coordination uncertainty, communication uncertainty and Uncertainty with remanufacturing. These uncertainties apply to PSSoSs development. More specifically, Product function uncertainty points out the risk of changing product's function over time through upgrades. Obsolescence appears as a cause for this uncertainty. Uncertainty of innovative services leads to technology changes. PSS integration uncertainty highlights the complexity and difficulty of adjustment when the degree of (Product and Service) integration is high. PSSs can also be seen as an "innovation strategy shifting the business focus from designing (and selling) physical products only, to 
designing (and selling) a system of products and services which are jointly capable of fulfilling specific client demands"” (Manzini and Vezzoli, 2003). Looking at uncertainty in the innovation management can then be relevant for PSSoS development. O'Connor and Rice (2013) suggest 4 categories of uncertainty, Market, Organizational and Resource uncertainties. Market uncertainties include features of customer/ Product interactions. Organizational uncertainty underlines the fundamental conflict between the mainstream organization the unit engaged into radical innovation. Resource uncertainty points out the competency gap in innovation projects. These uncertainties are also interesting with regard to PSSoS development as manufacturing industry address new markets by offering services apart from their core business.

O'Connor and Rice (2013) also add latency and criticality classes to uncertainty. "Latency refers to the degree to which the uncertainty can be perceived or anticipated". Criticality is the "the degree to which resolution of the uncertainty must occur immediately or the project's survival will be at risk".

In the SoS literature review, uncertainty is considered from a SoS enterprise engineering perspective. The uncertainties are mainly business partnership organization and partners role allocation (Carlock and Fenton, 2001).

Previously discussed literature underlines the need to identify PSSoS specific uncertainties as they are not addressed by current literature to our knowledge. Therefore, we propose to address this gap, firstly by identifying relevant PSSoS characteristics that are afterward used as a basis for uncertainty identification.

\section{RESEARCH METHODOLOGY}

The aim of this paper is to identify relevant uncertainties in the PSSoSs design process. The adopted approach Figure 1 is inspired by both the Design Research Methodology and the Action Research Method (Blessing L.T.M. and Chakrabarti, 2002; Brydon-Miller et al., 2015; Ferris, 2009; Järvinen, 2007). A literature survey has been conducted to characterise increasingly complex PSSs, including PSSoSs. Design uncertainties related to different PSSs types are assessed. Concomitantly, the research has been conducted within a large automotive industry. The field study is based upon data gathered from documents, observations, and interviews. This descriptive study allows to identify PSSs and PSSoSs programs' features and pertaining design uncertainties. The assessment of theoretical research along with the investigation of the field permits to build a PSSs and PSSoSs characterization map and a to identify related design uncertainties. The theoretical output aims at responding to the automotive industry needs and in a larger context, the manufacturing industry needs.

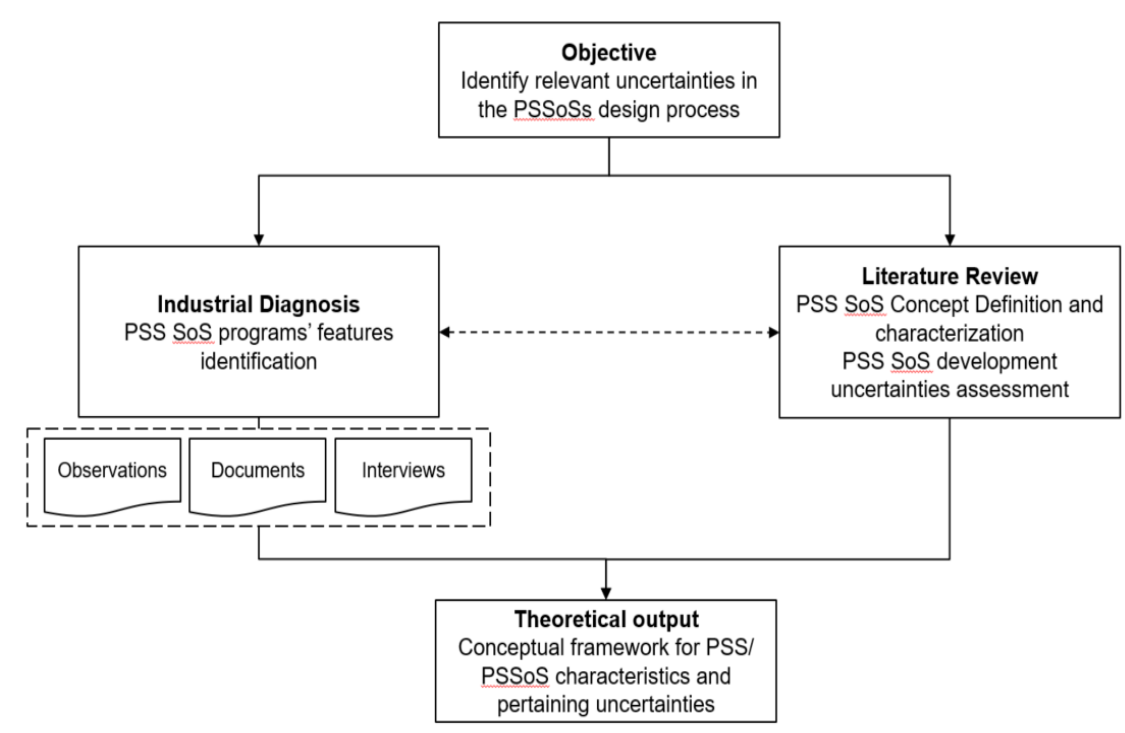

Figure 1: Research approach 


\section{PROPOSITION OF A PSS/PSSOS CHARACTERIZATION}

Previously discussed literature underlines different aspects of PSS and SoS. In the following, we go beyond the PSSoS definition in (Hein, Poulain, et al., 2018b) by mapping PSS-types to a system taxonomy by (Baldwin et al., 2011), including SoS.

In order to characterise PSSoSs, we base ourselves on the possible evolution of the PSS systems (product oriented, use-oriented, result-oriented) (Tukker, 2004; Wang et al., 2011) and the characterisation of types of systems (Baldwin et al., 2011; Baldwin and Sauser, 2009). The proposed PSSoS characterization map is two dimensional: PSS taxonomy dimension and system taxonomy dimension (Figure 2).

The PSS dimension describes how product-centric a PSS is or it's increasing heterogeneity. Along the Y-axis, the product centricity of PSSs decreases. PSSs characteristics add up moving from Product Oriented PSSs to Result-Oriented PSSs (Tukker, 2004).

While product-oriented PSSs (maintenance, reuse...) are customer oriented and sustainable, they only represent few features of heterogeneity. In use-oriented PSS, services, and usages diversify. The ownership of the product moves from the customer to the PSS providers which intensify the dynamic system/ customer interactions. The evolvability applies to Result oriented PSSs. In fact, the absence of a predefined product frees the PSS up to evolve throughout its lifecycle, according to customers' needs and stakeholder network configuration.

Using the systems taxonomy proposed in (Baldwin et al., 2011), we distinguish between PSSs and PSSoSs through the system dimension.

The system dimension describes the increase of systems complexity moving from simple systems to Systems of systems. Systems are characterized by their autonomy, connectivity, emergence, belonging, diversity and self-organization defined in (Baldwin et al., 2011).

According to this characterization authors distinguish between a simple system (Autonomy), a complicated system (Autonomy, Connectivity), a complex system (Autonomy, Connectivity, Belonging, Emergence), a system of system (Autonomy, Connectivity, Belonging, Emergence, Diversity) and a collaborative system (Autonomy, Connectivity, Belonging, Emergence, Diversity, Self-organization).

In (Baldwin et al., 2011), authors also introduce Adaptative systems and Complex Adaptative systems. Both systems share the adaptation characteristic. Adaption describes the ability of a system to "modify itself for the sake of its goals". The adaptive system also "has an awareness of itself in its environment and updates its behaviour based on this information". As no examples of human-made adaptative systems are given in (Baldwin et al., 2011), we consider adaptability out of the scope of this paper. The used characteristics help distinguish between simple systems and systems of systems.

In the literature, PSSs are usually studied as simple to complex systems. PSSs are little studied as SoSs or Collaborative SoSs. Yet, studied industrial examples show PSSoSs features.

In Figure 2, examples of mobility PSSs or PSSoSs developed by an automotive company (Renault) (except for Bike sharing) are presented (Chazal, 2018; Williams, 2007). Features of the mobility PSSs represented by black stars (Figure 2) have already been addressed in the Engineering Design and Systems Engineering literature (Herrmann et al., 2010; Pezzotta et al., 2011; Sakao et al., 2009; Shimomura et al., 2009; Zhang and Banerji, 2017). However, collaboration and evolutivity features of "On-demand Robot Vehicle", "Electric Vehicle to Grid (EV2G)" and "Battery as a Service" (Red Stars Figure 2) are rarely covered in the Engineering Design literature but rather in the Transportation Research Field (Bischoff and Maciejewski, 2016; Chen et al., 2016).

Figure 1 allows us to go beyond the uncertainties mentioned in the PSS literature, which mainly pertain to simple to complex systems. At this point, we can systematically identify PSSoS-related uncertainties that are not treated explicitly in the literature. The results are presented in the following section 5 . 


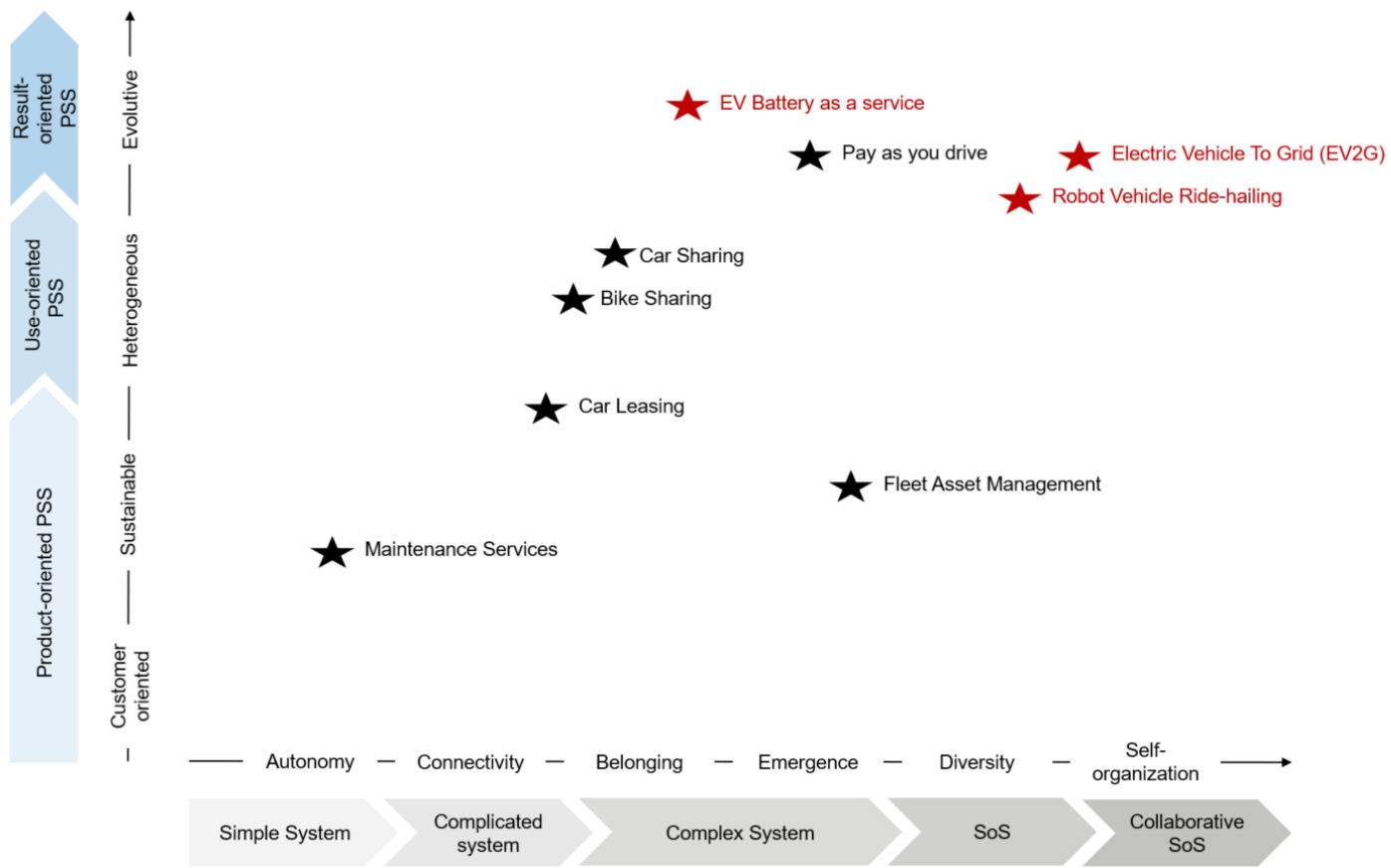

Figure 2: PSSs/ PSSoSs characterization map - Examples of mobility PSSs/ PSSoSs

\section{IDENTIFICATION OF PSSOS UNCERTAINTIES}

PSSoSs specific uncertainties could be deduced from both PSS literature and SoS literature (2.2). However, identified uncertainties do not cover exhaustively PSSoSs specific characteristics (Section 4). Based on the proposed PSSoS characterization section 3 and through an industrial diagnosis within an automotive company, we extend identified PSSs/ PSSoSs uncertainties and attempt to map PSSoSs characteristics and PSSoSs specific uncertainties.

The industrial diagnosis has been conducted as part of the new mobility solutions and services development team and in close contact to systems engineering experts in a large automotive company. Existing and future PSSoSs development programs have been assessed. Structured and semi-structured interviews have been conducted with both systems engineering experts and project managers to comprehend PSSoSs development difficulties.

Just like any other system, PSSoS development takes place under market uncertainties, environmental (political and cultural) uncertainties, company or corporate uncertainties and, product uncertainties (Kumar et al., 2013; De Weck et al., 2007).

Besides these uncertainties, the following uncertainties both from the literature and from the industrial context have been identified and seem to be specific PSSoSs uncertainties:

- Heterogeneous and independent systems interface uncertainties:

The heterogeneity of PSSs constituent elements is studied in the literature (Hernandez et al., 2018). However, the autonomy and independence (managerial and operational) of each system within a PSSoS are not considered. As heterogeneous systems are independent, systems interfaces are harder to design, manage and control by different stakeholders.

- Heterogeneous systems interoperability related uncertainties:

Heterogeneous systems integrations are extensively studied in the PSS literature (Geum and Park, 2011). However, in a PSSoS context, integrations and interoperability are even more challenging as they involve stakeholders' collaborations.

- $\quad$ Lifecycle offsets uncertainties:

Products and services lifecycles and development strategies are different (Cavalieri and Pezzotta, 2012). In the PSS literature, authors tend to suggest integrated PSS lifecycles models or more precisely integrated PSS development processes (Aurich et al., 2006; Hänsch et al., 2016; Hepperle et al., 2010; Kim et al., 2011; Shimomura et al., 2009; Wang et al., 2011). However, as Products and services in a PSSoS context could be independent systems, their lifecycles remain independent. Thus, lifecycle offsets are PSSoSs-specific uncertainties. 
- Uncertainty of innovative services/ products:

"Innovation often leads to technology changes, and, consequently, can be a source of uncertainties." (Kumar et al., 2013). Innovative services uncertainties lead to innovative products uncertainties as Products and Services are interoperable. This poses challenges for the manufacturing industry because their products need to keep pace with innovative services.

- Obsolescence uncertainties:

Within a PSSoS, products and services are interoperable, yet independent. Lifecycle offsets or fast evolutions of service technologies compared to product development could compromise products and services interoperability leading to systems' obsolescence.

- Usage uncertainties:

PSS development is seen as a mass customization strategy (Song and Sakao, 2017). Authors develop a PSS design framework able to support a variety of customers' needs and usages. However, in a PSSoS context, usages are not only diverse but also time dependent. Customers' needs, and perception of the service offer evolve and change throughout the PSSoS lifecycle.

- Collaboration uncertainties:

In a PSSoS context, systems contributions and stakeholders' roles allocation are not necessarily defined a priori. Systems/ actors could integrate and exit the PSSoS throughout its Lifecycle. Thus, in a PSSoS context, systems capabilities might need enhancement and changes to ensure interoperability and PSSoS functioning. This requires the right technical training, knowledge, and skills (Carlock and Fenton, 2001), a stakeholder/ company might lack. These issues are usually studied in the SoS Enterprise Engineering (SoSEE) or the SoS management literature (Carlock and Fenton, 2001; Sauser et al., 2009; Sauser and Boardman, 2008). Hence, Competency Gaps (O'Connor and Rice, 2013) are an additional PSSoS-specific uncertainty.

Uncertainties find their roots in either PSS characteristics or SoS characteristics (Figure 3). PSS Customer orientation, sustainability, heterogeneity, complexity, and evolutivity account for Heterogeneous and independent systems interface uncertainties, Heterogeneous systems interoperability related uncertainties, Lifecycle offsets uncertainties, Uncertainty of innovative services/ products, Obsolescence uncertainties and Usage uncertainties (Blue Rectangles Figure 3). However, the autonomy of each system and the diversity within a SoS make these uncertainties even more critical. Diversity and Self-organization explain the Collaboration uncertainties (Grey Rectangle Figure 3). Yet, competency gaps, for example, are particularly challenging as systems exhibit features of heterogeneity.

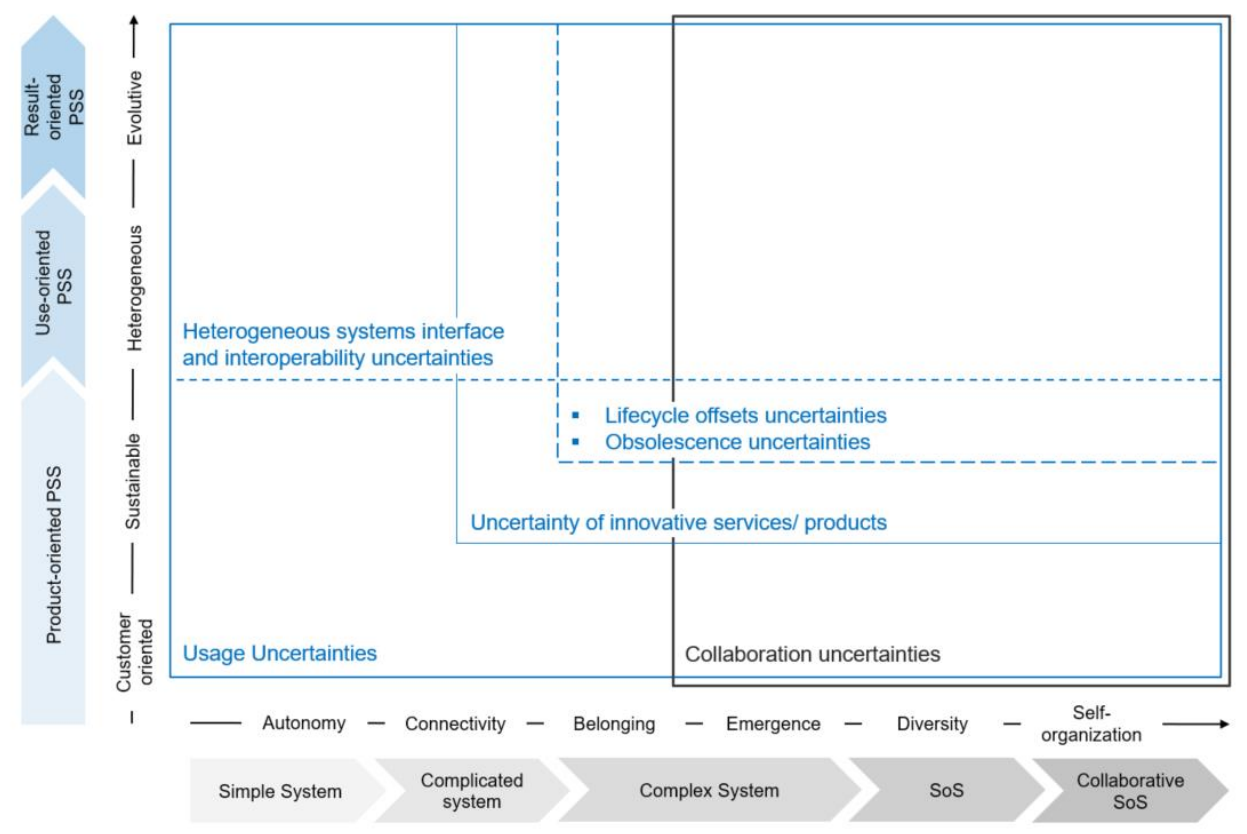

Figure 3: Mapping PSSs/ PSSoSs characteristics and PSSs/ PSSoSs specific uncertainties

The uncertainties described above, represent development challenges we need to specifically pay attention to, especially in the context of PSSoS and for the automotive industry. A generalization and a validation of PSSoSs-specific uncertainties are yet to be made. A PSSoS uncertainty model is needed. 
PSSoS uncertainty propagation methods are also to be developed. These models and methods should allow for the development of PSSoS uncertainty management strategies in design.

\section{CONCLUSION}

Product Service Systems (PSS) and Systems of Systems (SoS) are rarely linked in the literature. We call systems that exhibit both, PSS and SoS characteristics, Product Service System of Systems (PSSoS). For instance, the automotive industry develops increasingly complex PSSs (such as EV2G) that could be seen as PSSoSs. However, PSSoSs characterization and PSSoSs development difficulties need further discussion.

In this paper, by assessing PSS and system types, including SoS in the existing literature, we proposed a PSSoS characterization map. PSSoS features of heterogeneity, evolutivity, and complexity on one hand, managerial and operational independence of PSSoS constituent systems, on the other hand, raised uncertainty related issues for PSSoS development. The PSS and SoS literature mention some PSSoS-specific uncertainties such as customers changing needs, Products and Services lifecycles offsets and obsolescence issues. Besides, some PSSoS specific uncertainties could be identified through automotive industry examples analysis. However, an exhaustive study of PSSoS-specific uncertainties is still required.

For future work, a PSSoS-specific uncertainty model is needed. PSSoS uncertainties propagation methods could also be developed. Uncertainty models and propagation methods could help assess uncertainty management strategies in design.

\section{REFERENCES}

Aurich, J.C., Fuchs, C. and Wagenknecht, C. (2006), "Life cycle oriented design of technical product-service systems", Journal of Cleaner Production, Vol. 14 No. 17, pp. 1480-1494.

Aurich, J.C., Mannweiler, C. and Schweitzer, E. (2010), "How to design and offer services successfully", CIRP Journal of Manufacturing Science and Technology, CIRP, Vol. 2 No. 3, pp. 136-143.

Baldwin, W.C., Felder, W.N. and Sauser, B.J. (2011), "Taxonomy of increasingly complex systems", International Journal of Industrial and Systems Engineering, available at: https://doi.org/10.1504/IJISE.2011.043140.

Baldwin, W.C. and Sauser, B. (2009), "Modeling the characteristics of system of systems", SoSE, pp. 1-6.

Bischoff, J. and Maciejewski, M. (2016), “Autonomous taxicabs in berlin - A spatiotemporal analysis of service performance”, Transportation Research Procedia, The Author(s), Vol. 19 No. June, pp. 176-186.

Blessing L.T.M. and Chakrabarti, A. (2002), DRM: A design research methodology, No. 030, pp. $28-31$.

Brydon-Miller, M., Greenwood, D. and Maguire, P. (2015), "Why action research?”, Action Research, Vol. 1 No. 1, pp. 1-21.

Carlock, P.G. and Fenton, R.E. (2001), "System of systems (SoS) enterprise systems engineering for information-intensive organizations", Systems Engineering, Vol. 4 No. 4, pp. 242-261.

Cavalieri, S. and Pezzotta, G. (2012), "Product - service systems engineering : State of the art and research challenges", Computers in Industry, Elsevier B.V., Vol. 63 No. 4, pp. 278-288.

Chazal, Y. (2018), "Service systems, system od systems, cyber physical systems: Lessons leearned from electric vehicles to achieve new mobility challenges", IEEE SOSE, available at: http://sosengineering.org/2018/wp-content/uploads/2014/07/Y.Chazal.pdf.

Chen, T.D., Kockelman, K.M. and Hanna, J.P. (2016), “Operations of a shared, autonomous, electric vehicle fleet: Implications of vehicle \& charging infrastructure decisions", Transportation Research Part A: Policy and Practice, Elsevier Ltd, Vol. 94, pp. 243-254.

Estrada, A. and Romero, D. (2016), “A system quality attributes ontology for product-service systems functional measurement based on a holistic approach", Procedia CIRP, The Author(s), Vol. 47, pp. 78-83.

Ferris, T.L.J. (2009), “On the methods of research for systems engineering”, 7th Annual Conferenceon Systems Engineering Research 2009 (CSER 2009), Vol. 2009 No. April, p. 7.

Geum, Y. and Park, Y. (2011), "Designing the sustainable product-service integration: A product-service blueprint approach", Journal of Cleaner Production, Elsevier Ltd, Vol. 19 No. 14, pp. 1601-1614.

Haase, R.P., Pigosso, D.C.A. and McAloone, T.C. (2017), "Product/service-system origins and trajectories: a systematic literature review of pss definitions and their characteristics", Procedia CIRP, The Author(s), Vol. 64, pp. 157-162.

Hänsch, F., Pereira, D. and Borges, A. (2016), "Product-service systems characterization based on life cycle : application in a real situation", Procedia CIRP, Elsevier B.V., Vol. 47, pp. 418-423. 
Hein, A.M., Chazal, Y., Boutin, S. and Jankovic, M. (2018a), “A Methodology for Architecting Collaborative Product Service System of Systems", 13th Annual Conference on System of Systems Engineering (SoSE). IEEE, pp. 53-59.

Hein, A.M., Poulain, B., Jankovic, M., Chazal, Y. and Fakhfakh, S. (2018b), "Product service system design in a system of systems context: a literature survey", No. 1996, pp. 2891-2902.

Hepperle, C., Orawski, R., Nolte, B.D., Mörtl, M. and Lindemann, U. (2010), “An integrated lifecycle model of product-service-systems", pp. 159-166.

Hernandez, R., Kreye, T. and Pigosso, M. (2018), "Typology of Uncertainties in the Development Process of Product-Service Systems", 25th Annual EurOMA Conference, available at: http://www.inderscience.com/link.php?id=43140.

Herrmann, C., Kuntzky, K., Mennenga, M., Royer-Torney, M., Bergmann, L., Herrmann, C., Kuntzky, K., et al. (2010), "Joint Framework for Product Service Systems and Life Cycle Management", CIRP International Conference on Industrial Product Service Systems, pp. 353-359.

Herzog, M., Meuris, D., Bender, B. and Sadek, T. (2014), "The nature of risk management in the early phase of IPS2 design", Procedia CIRP, available at:https://doi.org/10.1016/j.procir.2014.02.010.

Järvinen, P. (2007), “Action research is similar to design science”, Quality and Quantity, Vol. 41 No. 1, pp. 37-54.

Keating, C.B. and Katina, P.F. (2011), "Systems of systems engineering: prospects and challenges for the emerging field”, International Journal of System of Systems Engineering, available at:https://doi.org/10.1504/IJSSE.2011.040556.

Kim, Y.S., Lee, S.W. and Koh, D.C. (2011), "Representing product-service systems with product and service elements", ICED 11 - 18th International Conference on Engineering Design - Impacting Society Through Engineering Design, Vol. 4 No. August, pp. 390-399.

Kreye, M.E. (2011), Uncertainty Analysis in Competitive Bidding for Service Contracts.

Kumar, A.A., Trinh, G.C. and Sakao, T. (2013), "How is Uncertainty Perceived and Managed in Design by PSS Providers? - Relation to PSS Types Provided”, The Philosopher's Stone for Sustainability, Springer, Berlin, Heidelberg, pp. 91-96.

Maier, M.W. (1996), “Architecting principles for systems-of-systems”, INCOSE International Symposium, Vol. 6 No. 1, pp. 565-573.

Maleki, E., Belkadi, F. and Bernard, A. (2017), "Systems engineering as a foundation for PSS development project: motivations and perspectives", Procedia CIRP, Elsevier B.V., Vol. 64, pp. 205-210.

Manzini, E. and Vezzoli, C. (2003), “A strategic design approach to develop sustainable product service systems: Examples taken from the 'environmentally friendly innovation' Italian prize”, Journal of Cleaner Production, Vol. 11 No. 8 SPEC., pp. 851-857.

Meier, H., Roy, R. and Seliger, G. (2010), “Industrial Product-Service systems-IPS2”, CIRP Annals Manufacturing Technology, Vol. 59 No. 2, pp. 607-627.

Mont, O. (2002), "Clarifying the concept of product - service system", Journal of Cleaner Production, Vol. 10, pp. 237-245.

O’Connor, G.C. and Rice, M.P. (2013), “A comprehensive model of uncertainty associated with radical innovation", Journal of Product Innovation Management, available at:https://doi.org/10.1111/jpim.12060.

Park, Y., Geum, Y. and Lee, H. (2012), “Toward integration of products and services: Taxonomy and typology”, Journal of Engineering and Technology Management - JET-M, Elsevier B.V., Vol. 29 No. 4, pp. 528-545.

Pezzotta, G., Regazzoni, D., Cavalieri, S. and Rizzi, C. (2011), "Enhancement in Industrial PSS Design based on TRIZ: a Case Study", Proceedings of the 3rd CIRP IPSS Conference CIRP IPSS Conference, pp. 225-230.

Pieroni, M.D.P., Marques, C.A.N., Moraes, R.N., Rozenfeld, H. and Ometto, A.R. (2017), "PSS design process models: Are they sustainability-oriented?", Procedia CIRP, Vol. 64, pp. 67-72.

Reim, W., Sjödin, D.R. and Parida, V. (2014), “Trust or Control: How to Manage Behavioural Uncertainty for Industrial Product-Service System Provision?”, International CINet Conference: Operating InnovationInnovating Operations 07/09/2014-09/09/2014.

Sakao, T., Panshef, V. and Dörsam, E. (2009), “Addressing uncertainty of PSS for value-chain oriented service development”, Introduction to Product/Service-System Design, pp. 137-157.

Sassanelli, C., Pezzotta, G., Pirola, F., Terzi, S. and Rossi, M. (2016), "Design for Product Service Supportability (DfPSS) approach : a state of the art to foster Product Service System (PSS) design", Procedia CIRP, The Author(s), Vol. 47, pp. 192-197.

Sauser, B. and Boardman, J. (2008), "Taking hold of system of systems management”, Engineering Management Journal, Vol. 20 No. 4.

Sauser, B., Boardman, J. and Gorod, A. (2009), “System of Systems Management”, System of Systems Engineering: Innovations for the 21st Century, pp. 191-217.

Shimomura, Y., Hara, T. and Arai, T. (2009), "A unified representation scheme for effective PSS development", CIRP Annals - Manufacturing Technology, Vol. 58 No. 1, pp. 379-382.

Song, W. (2017), "Requirement management for product-service systems : Status review and future trends", Computers in Industry, Elsevier B.V., Vol. 85, pp. 11-22. 
Song, W. and Sakao, T. (2017), “A customization-oriented framework for design of sustainable product / service system”, Journal of Cleaner Production, Elsevier Ltd, Vol. 140, pp. 1672-1685.

Tukker, A. (2004), "Eight types of product service systems", Business Strategy and the Environment, Vol. 13, pp. 246-260.

Tukker, A. (2015), "Product services for a resource-efficient and circular economy - A review", Journal of Cleaner Production, Elsevier Ltd, Vol. 97, pp. 76-91.

Wang, P.P., Ming, X.G., Li, D., Kong, F.B., Wang, L. and Wu, Z.Y. (2011), "Status review and research strategies on product-service systems", International Journal of Production Research, Vol. 49 No. 22, pp. 6863-6883.

De Weck, O., Eckert, C. and Clarkson, J. (2007), “A classification of uncertainty for early product and system design”, Guidelines for a Decision Support Method Adapted to NPD Processes, pp. 159-160.

Williams, A. (2007), "Product service systems in the automobile industry : contribution to system innovation?", Journal of Cleaner Production, Vol. 15 No. 11-12, pp. 1093-1103.

Zhang, W. and Banerji, S. (2017), "Challenges of servitization: A systematic literature review”, Industrial Marketing Management, available at: https://doi.org/10.1016/j.indmarman.2017.06.003. 